\title{
ORIGIN OF THE MAJOR PLANET ATMOSPHERES: CLUES FROM TRACE SPECIES
}

\author{
S.K. ATREYA and S.G. EDGINGTON \\ Department of Atmospheric, Oceanic and Space Sciences \\ The University of Michigan, Ann Arbor, MI 48109-2143 \\ D. GAUTIER \\ Observatoire de Paris-Meudon, France
}

\author{
T.C. OWEN \\ Institute for Astronomy, University of Hawaii \\ Honolulu, HI 96822
}

\begin{abstract}
According to the generally accepted planetesimal accretion hypothesis, the present atmospheres on the major planets, Jupiter, Saturn, Uranus and Neptune, resulted from two sources: outgassing from planetary interiors during the accretionary heating phase the planetesimals making up the core were composed of grains, ices and possibly clathrates - and direct capture of gases from the solar nebula. It is not apparent, however, whether the present atmospheres of these planets are representative of the composition of the dense interstellar cloud from whose collapse the solar nebula initially formed, or whether the interstellar material was further processed in the solar nebula before being accreted into the major planets. Although present observations cannot fully constrain the models of the origin of atmospheres, clues to the physical and chemical nature of the solar nebula and subsequent origin and evolution of the major planet atmospheres are beginning to emerge from studies of the elemental isotopic ratios (such as $\mathrm{D} / \mathrm{H}$ ) and the mole fractions of such trace species as $\mathrm{He}, \mathrm{CH}_{4}, \mathrm{NH}_{3}, \mathrm{CO}$ and $\mathrm{HCN}$. Since much has been written on $\mathrm{D} / \mathrm{H}, \mathrm{He} / \mathrm{H}_{2}$ and $\mathrm{CH}_{4} / \mathrm{H}_{2}$ [1], this paper focuses on what one can learn about the origin of the major planet atmospheres from the detected presence of $\mathrm{CO}$ and $\mathrm{HCN}$ in Neptune's atmosphere. On the basis of our calculations, we conclude that the interior of Neptune should contain $\mathrm{CO}$ and $\mathrm{N}_{2}$, with the $\mathrm{N}_{2}$ mole fraction close to the value for the cosmic $\mathrm{C} / \mathrm{N}$ ratio. The presence of these interstellar molecules in the interior of Uranus is suggested also.
\end{abstract}

$\mathrm{CO}$ and $\mathrm{HCN}$ have been detected at ppm and ppb levels, respectively, in the stratosphere of Neptune $[2,3]$ and their tentative implications for atmospheric chemistry have been discussed $[2,4,5,6,7]$. Extraplanetary sources of water vapor (e.g. from ablating meteoroids or comets) and nitrogen (e.g. from Triton) could, in principle, produce $\mathrm{CO}$ and $\mathrm{HCN}$ following their reactions with the photolysis products of $\mathrm{CH}_{4}$; they are, however, inadequate for producing the observed mole fractions of $\mathrm{CO}$ and $\mathrm{HCN}[2,4,5,6,7]$. The alternative is an intrinsic source in the form of $\mathrm{CO}$ and $\mathrm{N}_{2}$. This is attractive from many different points of view: (a) it does not require a unique origin for Neptune's atmosphere relative to Uranus' - a planet that is similar to Neptune in "bulk" composition - since the lack of detection of $\mathrm{CO}$ and $\mathrm{HCN}$ on Uranus can be attributed to the lack or virtual lack of convection in Uranus' interior which would prevent detectable abundances of $\mathrm{CO}$ and $\mathrm{N}_{2}$ from being transported to the stratosphere (presence of $\mathrm{CH}_{4}$ there could create a potential problem, but it probably has another explanation, as discussed later); (b) it reduces the value of the helium mole fraction on Neptune to $15 \%$ [8], which is consistent with the protosolar and the Uranian values, provided that the $\mathrm{N}_{2}$ mole fraction is $0.3 \%\left(\mathrm{~N}_{2}\right.$ of $0.3 \%$ is what one would expect for 
solar $\mathrm{C} / \mathrm{N}$ ratio with $\mathrm{C} / \mathrm{H}=30 \mathrm{x}$ solar); (c) it explains the observed depletion of $\mathrm{NH}_{3}$ on Neptune (and Uranus, if $\mathrm{C} / \mathrm{N} \geq$ solar) since most of the nitrogen would be in the form of $\mathrm{N}_{2}$. The proposed presence of $\mathrm{CO}$ and $\mathrm{N}_{2}$ in the interiors of Uranus and Neptune implies that these species were incorporated directly from the solar nebula, and that the $\mathrm{N}_{2}$ and $\mathrm{CO}$ of the interstellar cloud were not reduced to $\mathrm{NH}_{3}$ and $\mathrm{CH}_{4}$, respectively, in the less than $30 \mathrm{Myr}$ lifetime of the solar nebula before its gas was blown away. Indeed, it seems that equilibrium may not have reached anywhere in the solar nebula despite the possibility of Fischer-Tropsch-type catalytic reactions, since the pressures and temperatures in the solar nebula were inadequate for such reactions. The fact that both Jupiter and Saturn have solar or super-solar $\mathrm{NH}_{3}$ and $\mathrm{CH}_{4}$ in their atmospheres appears to imply that once incorporated as $\mathrm{N}_{2}$ and $\mathrm{CO}$ from the solar nebula these gases must have been reduced to $\mathrm{NH}_{3}$ and $\mathrm{CH}_{4}$, respectively, by Haber-type processes in the deep, dense, hot interiors of these planets. Such reduction requires presence of an iron catalyst which is expected to be present in their cores. Although the cores of Uranus and Neptune are also expected to have iron, the gases could be separated from the iron by layering in the interior. Since the $\mathrm{CO}$ to $\mathrm{CH}_{4}$ catalysis proceeds somewhat differently than $\mathrm{N}_{2}$ to $\mathrm{NH}_{3}$, there is the possibility that some $\mathrm{CO}$ hydrogenation occurred in the solar nebula, but most of the $\mathrm{CO}$ was reduced to $\mathrm{CH}_{4}$ in the interiors of Uranus and Neptune as well, leaving some CO behind. It is this CO that is detected in the atmosphere of Neptune, as well as on Jupiter and Saturn. The detection of $\mathrm{N}_{2}$ and $\mathrm{CO}$ on Pluto and Triton lends support to this hypothesis, since the Haber-type reactions cannot occur on these tiny solid bodies, so that they are expected to retain to a large extent the original gases incorporated during their accretion.

Regarding the large $\mathrm{CH}_{4}$ abundance on the major planets, there is yet another likelihood for the formation of methane on these planets. Since most of the carbon in the interstellar cloud is in the form of grains, perhaps carbon delivered as grains was responsible for the formation of methane.

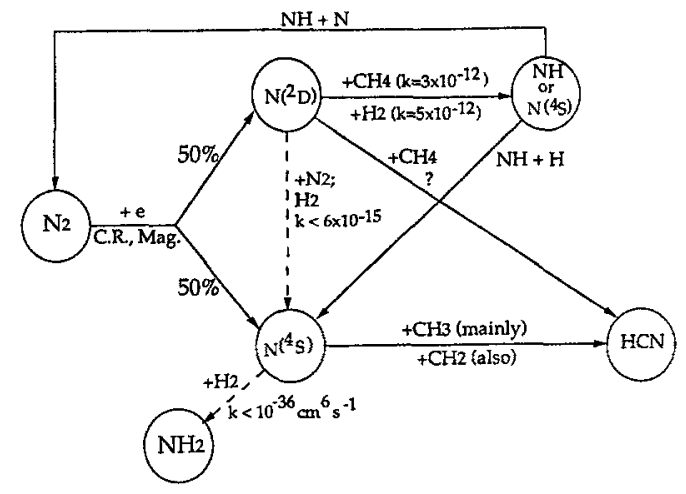

Figure 1. Nitrogen chemistry leading to the formation of HCN.

Dissociation of $\mathrm{N}_{2}$ in the stratosphere, after this gas convects from Neptune's interior, is necessary for producing $\mathrm{HCN}$ as detailed in Figure 1 (intermediate product $\mathrm{H}_{2} \mathrm{CN}$ is not shown). The dissociating/ionizing flux is most likely provided by the galactic cosmic rays (GCR). The production rate of ion-electron pairs created in gas $\mathrm{j}$ by primary GCR [9] can be approximated by (assuming that energy is deposited locally): 


$$
\mathrm{q}_{\mathrm{j}}(\mathrm{z})=\frac{1}{\Delta \mathrm{E}_{\mathrm{j}}} \int_{\Omega} \int_{\mathrm{E}_{0}}^{\infty} \Phi(\mathrm{E}, \mathrm{z}, \Omega)\left[-\frac{\mathrm{dE}}{\mathrm{dz}}\right]_{\mathrm{j}} \mathrm{dEd} \Omega
$$

where $\Delta \mathrm{E}_{\mathrm{j}}$ is the average energy needed to create an ion-electron pair in gas $\mathrm{j}$ and is typically $36 \mathrm{eV},[-\mathrm{dE} / \mathrm{dz}]_{j}=\mathrm{nj}_{\mathrm{j}} \sigma_{\mathrm{j}} \mathrm{is}$ the stopping power, $\Omega$ is the solid angle, $E$ is the energy of the cosmic ray, and $\Phi(E, z, \Omega)$ is the differential flux of GCR. The total absorption cross-section for the incident galactic cosmic rays in the atmosphere of Neptune is taken to be $8.5 \times 10^{-26} \mathrm{~cm}^{2}$, and it is based on the work of Schopper [10] and Belletini et al [11]. Secondary electrons, produced in the collision of galactic cosmic rays with the atmospheric constituents, dissociate and ionize $\mathrm{N}_{2}$ and $\mathrm{H}_{2}$ in the following manner:

$$
\begin{aligned}
& \mathrm{e}+\mathrm{N}_{2} \rightarrow \mathrm{N}_{2}^{+}+2 \mathrm{e} \quad \mathrm{q}=0.53 \quad \sigma=2.6 \times 10^{-16} \mathrm{~cm}^{2} \\
& \left.\rightarrow \mathrm{N}^{4} \mathrm{~S}\right)+\mathrm{N}^{+}+2 \mathrm{e} \quad=0.12 \quad=6.0 \times 10^{-17} \mathrm{~cm}^{2} \\
& \rightarrow \mathrm{N}\left({ }^{4} \mathrm{~S}\right)+\mathrm{N}\left({ }^{2} \mathrm{D}\right)+\mathrm{e} \quad=0.35 \quad=1.8 \times 10^{-16} \mathrm{~cm}^{2}
\end{aligned}
$$

and

$$
\begin{aligned}
\mathrm{e}+\mathrm{H}_{2} & \rightarrow \mathrm{H}_{2}^{+}+2 \mathrm{e} & \sigma & =1.0 \times 10^{-16} \mathrm{~cm}^{2} \\
& \rightarrow \mathrm{H}^{+}+\mathrm{H}+\mathrm{e} & & =6.0 \times 10^{-18} \mathrm{~cm}^{2}
\end{aligned}
$$

where $q$ is the quantum efficiency and $\sigma$ is the cross section for a given path $[12,13]$. The previous values of q's for reactions (2), (3) and (4), $0.45,0.10$ and 0.45 , respectively, do not alter the results significantly.

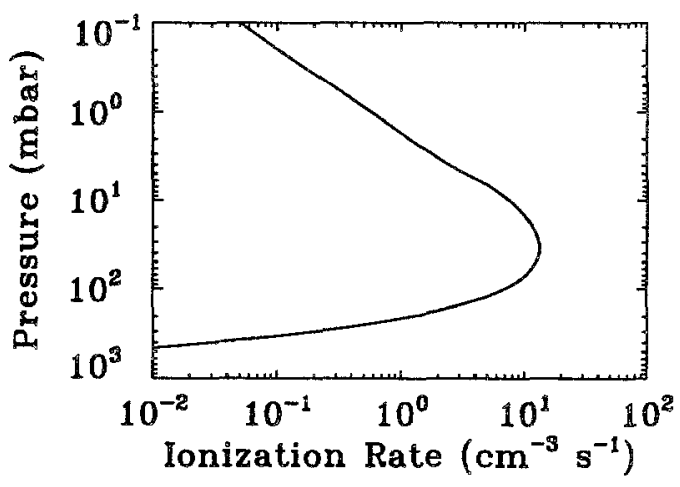

Figure 2: Ion-pair production rate due to penetration of primary galactic cosmic rays into Neptune's atmosphere at a magnetic latitude of $60^{\circ}$.

Using the differential flux of the GCR at Neptune [14], we obtain total ion-pair production rate shown in Figure 2 and a column production rate of ion pairs, $\mathrm{q}_{\mathrm{T}}=6.7 \times 10^{7} \mathrm{~cm}^{-2} \mathrm{~s}^{-1}$. The $\mathrm{N}\left({ }^{4} \mathrm{~S}\right)$ production rate is $73 \%$ of the total nitrogen ion production rate, $q_{N_{x}^{+}}$; whereas $q_{N_{x}^{+}}=3.3 q_{H_{x}^{+}} f_{N_{2}}$, where $q_{H_{x}^{+}}$is the total hydrogen ion $\left(\mathrm{H}_{2}^{+}\right.$and $\left.\mathrm{H}^{+}\right)$production rate and $\mathrm{f}_{\mathrm{N}_{2}}$ is the $\mathrm{N}_{2}$ mole fraction. Since $\mathrm{q}_{\mathrm{x}} \approx \mathrm{q}_{\mathrm{T}}$, the $\mathrm{N}\left({ }^{4} \mathrm{~S}\right)$ production is $1.6 \times 10^{8} \mathbf{f}_{\mathrm{N}_{2}}$. The $\mathrm{N}\left({ }^{4} \mathrm{~S}\right)$ required to produce the observed $\mathrm{ppb}$ level of HCN is $1.7 \times 10^{6} \mathrm{~cm}^{-2} \mathrm{~s}^{-1}$ for $\mathrm{K}=10^{5} \mathrm{~cm}^{2} \mathrm{~s}^{-1}$ [2] in the production region of HCN $(1-2 \mathrm{mb})$ and $1.7 \times 10^{5} \mathrm{~cm}^{-2} \mathrm{~s}^{-1}$ if $\mathrm{K}=10^{4} \mathrm{~cm}^{2} \mathrm{~s}^{-1}$, where $\mathrm{K}$ is the eddy diffusion coefficient. Therefore $0.1 \%-1 \%$ mole fraction of $\mathrm{N}_{2}$ will be needed. The actual required $\mathrm{f}_{\mathrm{N}_{2}}$ is probably closer to $0.1 \%$ than $1 \%$ since $\mathrm{K}<10^{5} \mathrm{~cm}^{2} \mathrm{~s}^{-1}, \mathrm{~N}\left({ }^{2} \mathrm{D}\right)$ could quench and produce $100 \%$ more $\mathrm{N}\left({ }^{4} \mathrm{~S}\right)$, and the actual cascading process of the 
charged particles through the atmosphere than the simplified scenario of local deposition of energy considered here could produce $50-100 \%$ more $\mathrm{N}\left({ }^{4} \mathrm{~S}\right)$. Proper treatment of the cascading of charged particles through the atmosphere requires a Monte Carlotype approach where the history of cosmic ray particles and secondary electrons through the atmosphere is followed.

In summary, we propose that the major planets acquired at least a part of their atmospheres from vaporization of ices embedded in the nebula. Whatever the form of $C$ and $\mathrm{N}$ compounds in these ices, the material was reprocessed in the planetary interiors. A possible exception to this scenario is provided by laboratory studies of the trapping of gases by ices at low temperature [15]. This work indicates that the relative fractions, as well as abundances of $\mathrm{CO}$ and $\mathrm{N}_{2}$ (as well as other volatiles) trapped in ices, has a strong dependence on temperature. If we believe that these volatiles were delivered to Uranus and to Neptune (and other major planets) by the icy planetesimals, then there is the possibility that far less $\mathrm{CO}$ and $\mathrm{N}_{2}$ were delivered to Uranus than Neptune, which formed in the colder part of the solar nebula [16].

Observational tests as well as improved theoretical models will be needed to confirm and improve upon the hypothesis proposed here. Direct spectroscopic detection of $\mathrm{N}_{2}$ on the major planets is not possible at this time. However, detection and quantification of nitrogen bearing molecules, such as nitriles, as well as $\mathrm{C} / \mathrm{H}$ (as in $\mathrm{CH}_{4}$ ), $\mathrm{P} / \mathrm{H}$ (as in $\mathrm{PH}_{3}$ ) and the isotopic ratios in the noble gases are relevant and crucial. Thermochemical models for the interior and models of the chemistry initiated by the solar ultraviolet photons and charged particles, including Monte Carlo calculations for determining the $\mathrm{N}$-atom yield are essential. Comparative planetology in this instance has the potential of addressing some of the most fundamental questions of the formation of the planets and their atmospheres.

\section{Acknowledgment}

S.K. Atreya acknowledges support received from the NASA Solar System Exploration Division, Planetary Atmospheres Program for research reported here.

\section{REFERENCES}

1. Gautier, D. and Owen, T.C. (1989) The composition of the outer planet atmospheres, in S.K. Atreya, J.B. Pollack and M.S. Matthews (eds.), Origin and Evolution of Planetary and Satellite Atmospheres, University of Arizona Press, Tucson, pp. 487-512.

2. Marten, A., Gautier, D., Owen, T., Sanders, D.B., Matthews, H.E., Atreya, S.K., Tilanus, R.P.J. and Deane, J.R. (1993) First observations of $\mathrm{CO}$ and $\mathrm{HCN}$ on Neptune and Uranus at millimeter wavelengths and their implications for atmospheric chemistry, Astrophys. J. 406, 285-297.

3. Rosenqvist, J., Lellouch, E., Romani, P.N., Paubert, G. and Encrenaz, T. (1992) Millimeter-wave observations of Saturn, Uranus, and Neptune: CO and HCN on Neptune, Astrophys. J. 392, L99-L102.

4. Atreya, S.K., Owen, T.C., Gautier, D. and Marten, A. (1992) HCN and CO on Neptune: An intrinsic origin, Bull. Ant. Astron. Soc. 24, 972, and Paper presented at the Division of Planetary Sciences Meeting, AAS, Munich, Germany, October, 1992.

5. Gautier, D., Conrath, B.J., Owen, T., De Pater, I and Atreya, S.K. (1994) The Troposphere of Neptune, D. Cruikshank (ed.), Neptume, University of Arizona Press, Tucson, in press.

6. Bishop, J., Atreya, S.K., Romani, P.N., Orton, G.S., Sandel, B.R. and Yelle, R.V. (1994) The Middle and Upper Atmosphere of Neptune, D. Cruikshank (ed.), Neptume, University of Arizona Press, Tucson, in press.

7. Lellouch, E., Romani, P.N. and Rosenqvist, J. (1994) The vertical distribution and origin of HCN in Neptune's atmosphere, lcarus 108, 112-136.

8. Conrath, B.J., Gautier, D., Owen, T.C. and Samuelson, R.E. (1993) Constraints on $\mathrm{N}_{2}$ in Neptune's atmosphere from Voyager measurements, Icarus 101, 168-172.

9. Moses, J.I., Allen, M. and Yung, Y.L. (1992) Hydrocarbon nucleation and aerosol formation in Neptune's atmosphere, Icarus 99, 318-346.

10. Schopper, H. (1973) Elastic and charge exchange scattering of elementary particles, in H. Helwege (ed.), Landolt-Bomstein Numerical Data and Functional Relationships in Science and Technology, Springer-Verlag, New York, pp.7-30.

11. Belletini, G., Cocconi, G., Diddens, A.N., Lillethun, E., Matthide, G., Scanlon, I.P. and Wetherell, A.M. 
(1966) Proton-nuclei cross sections at $20 \mathrm{GeV}$, Nucl. Phys. 29, 609-624.

12. Rapp, D., Englander-Golden, P. and Briglia, D.D. (1965) Cross sections for dissociative ionization of molecules by electron impact, J. Chem. Phys. 42, 4081-4085.

13. Stevens, M.H., Strobel, D.F., Summers, M.E. and Yelle, R.V. (1992) On the thermal structure of Triton's thermosphere, Geophys. Res. Lett. 19, 669-672.

14. Selesnick, R.S. and Stone, E.C. (1991) Neptune's cosmic ray cutoff, Geophys. Res. Lett. 18, 361-364.

15. Bar-Nun, A., Kleinfeld, I. and Kochavi, E. (1988) Trapping of gas mixtures by amorphous water ice, Phys. Rev. B 38, 7749-7754.

16. Owen, T.C. and Bar-Nun, A. (1994) Comets, Impacts, and Atmospheres, Icarus, submitted. 